\title{
A IDEIA, A SÉRIE E A FORMA: DESAFIOS DA IMAGEM NO PENSAMENTO DE CLAUDE LÉVI-STRAUSS
}

Tradução de Estela Abreu

\begin{abstract}
A obra de arte é, em si, um ato de conhecimento e de julgamento. É preciso, portanto, transferir o conceito de conhecimento estético da teoria para a obra. Carl Einstein, Totalität, I, 1914.
\end{abstract}

Não se encontra, na obra de Claude Lévi-Strauss, "antropologia da arte" no sentido que hoje damos a esse termo. O estudo das imagens, sempre feito a partir das próprias obras e nunca a partir de teorias estéticas, não constitui para ele uma subdisciplina da antropologia social. Trata-se, ao contrário, de um trabalho de análise que se refere ao próprio objeto da antropologia. Existem, em sua obra, textos sobre as artes asiáticas ou oceânicas, leituras de obras de Clouet ou de Poussin, observações sobre Greuze, Delvaux, Manet, os surrealistas, os cubistas ou os impressionistas. São tantas as referências às artes plásticas que já é costume distinguir, de um lado, o etnólogo, que estudou, utilizando uma linguagem relativamente técnica, as artes dos índios do Brasil ou dos índios da Costa Noroeste da América do Norte e, de outro lado, o conhecedor apaixonado que comentou, de maneira mais rápida, as obras deste ou daquele artista ocidental. Isto equivale a esquecer que, desde La pensée sauvage [O pensamento selvagem] (1962), a arte é reconhecida por Lévi-Strauss como um dos grandes temas sujeitos à reflexão antropológica, tanto quanto o mito, o jogo ou o ritual. A grande riqueza dos temas artísticos evocados em sua obra não comprova apenas sua imensa erudição; ela remete ao anseio de universalidade que anima todo o seu pensar. Para homenageá-lo, vou tentar, neste artigo, apreciar o desafio dessa ambição, que busca definir "sempre e em toda a parte, o tipo da obra de arte" (Lévi-Strauss, 2008: 583) e procurar mostrar alguns desenvolvimentos possíveis.

Desde o final dos anos 1950, Lévi-Strauss sobressai, como teórico da arte, em relação a seus contemporâneos. Em 1957, André Breton publicou um longo ensaio, em grande parte dedicado às artes não ocidentais, sob o título de L'art 
magique [A arte mágica]. Ao conhecimento científico que, segundo ele, "pretende sempre estender seu domínio sobre toda invenção humana" (Breton, 2008: 62), o fundador do Surrealismo opunha uma "consciência lírica" universal permitindo uma compreensão direta de qualquer arte. Primitiva ou moderna, ingênua ou exótica, a arte responde, em qualquer tempo e em qualquer lugar, segundo Breton, a um instinto "ligado à perenidade de certas aspirações humanas de ordem maior" (Breton, 2008: 53). Sem se identificar diretamente a ela, a magia responde, portanto, “às mesmas aspirações que a prática da arte". Em toda parte "a obra obedece às suas próprias leis: que ela decida ou não adaptar-se a finalidades mágicas, não se pode esquecer que é na própria magia que ela tem origem; mesmo que quisesse ser puramente realista, ela continuaria a dever a maioria de seus recursos à magia" (Breton, 2008: 73).

Contra o que ele chamava de "civilização de professores" que, para explicar a vida da árvore, "só se sente bem à vontade quando toda a seiva já foi extraída da árvore", era preciso, portanto, reconhecer que "toda arte é mágica, pelo menos em sua gênese" (Breton, 2008: 73). Quando falava de magia, Breton se referia, sobretudo, às "disciplinas herméticas da tradição ocidental" cuja influência sobre a arte europeia ele defendeu por muito tempo. Nunca será possível compreender - escreveu ele - Vítor Hugo, Baudelaire ou Mallarmé sem fazer referência a Eliphas Lévi e à tradição esotérica que ele representa. Mas seria um erro acreditar que o esoterismo mágico tenha sido um fenômeno específico do Ocidente. A seus olhos, a tradição dos magos herméticos não foi senão uma tradução para nós, em termos que nos são familiares, de uma concepção que existe em todo o mundo. Eliphas Lévi assim formulava esse "dogma único": "como o visível sempre é a manifestação do invisível... a verdade se encontra, nas coisas apreciáveis e visíveis em proporção exata com as coisas inapreciáveis a nossos sentidos e invisíveis a nossos olhos" (Breton, 2008: 64).

O desenvolvimento da civilização e o progresso das técnicas nunca conseguiram, segundo Breton, extirpar da alma humana "a esperança de resolver o enigma do mundo e de desviar, em proveito próprio, as forças que o governam". $\mathrm{O}$ instinto que leva à manipulação mágica do mundo permanece, portanto, bem vivo, no Ocidente e alhures. Os "povos selvagens perderam bem menos que nós a carga mágica que justifica sua existência". Por isso - conclui ele -, "a precariedade de seus recursos hoje contrasta com sua arte luxuriosa" (Breton, 2008: 83).

Como apêndice à introdução de $\mathrm{A}$ arte mágica, Breton publicou uma enquete, com uma série de perguntas dirigidas, segundo suas palavras, "a alguns dos espíritos mais bem qualificados" de seu tempo. Certas perguntas eram uma retomada explícita das teses defendidas na Introdução: seria possível afirmar que "a civilização só dissipou a ficção da magia para exaltar, na arte, a magia da ficção"?; a magia responderia a uma "necessidade inalienável do espírito"? Outras perguntas referiam-se mais especificamente à relação entre arte moderna e pensamento mágico: de seu "longo estacionamento nas vias de garagem da 
imitação" - escrevia Breton -, poderia a arte de hoje sair outra, graças a uma reabilitação da magia? Seria possível, no âmbito da arte moderna, qualificar obras ou artistas (Rousseau, De Chirico, Kandinsky, Chagall, Duchamp) de "mágicos"? Ou seria preciso ir além do domínio da arte, e identificar um papel mágico, ligado, por exemplo, à memória, desempenhado por certos objetos na vida cotidiana? Etnólogos, filósofos, historiadores da arte, artistas ou escritores, os interlocutores escolhidos por Breton davam respostas muito diferentes a todas essas perguntas. Alguns, como Heidegger, duvidavam dos critérios conceptuais que levavam Breton a opor a arte "mágica" à arte "religiosa", ou mesmo à arte "clássica" ou "barroca". Confundiam-se assim, segundo o filósofo, "categorias que nomeavam períodos históricos da arte, com categorias de ordem teórica ou metafísica" que procuravam mais qualificar sua natureza (Breton, 2008: 116). Outros, como Jean Paulhan, criticavam a facilidade com a qual a noção de magia era evocada no questionário: "não vejo qual a utilidade" - escrevia Paulhan - "de confrontar duas coisas tão diferentes quanto uma magia pessoalmente experimentada e uma magia suposta, apoiado em provas infinitamente levianas, nesta ou naquela época, nesta ou naquela cultura" (apud Breton, 2008: 118).

Inúmeros autores estavam, porém, de acordo em um ponto: existe uma "arte mágica", que atravessa as épocas e as culturas do mundo. As obras que ilustram o livro de Breton - quadros de Bosch, de Arcimboldo, de François Nomé, de Paolo Uccello ou de Goya; máscaras africanas ou oceânicas, obras de De Chirico, Kandinsky, Dali e de Max Ernst, ofereciam, dependendo do desejo do autor, uma prova irrefutável.

Entre os textos publicados como apêndice dessa introdução, uma resposta se distanciava bastante das outras: a de Claude Lévi-Strauss. Às perguntas feitas por Breton, o antropólogo que havia estudado muito as artes ameríndias, respondeu com uma série de reflexões voltadas tanto para as modalidades da enquete como para a existência de uma "arte mágica". De qual arte se trata - perguntava Lévi-Strauss - de qual magia? E, sobretudo, de qual sociedade? "Através da história e segundo as sociedades, a arte e a magia em certos momentos se acompanharam, em certos momentos se separaram, ou cruzaram seus caminhos. Mas, para compreender essa relação, seria preciso primeiro definir a situação nos termos de cada sociedade considerada", escreveu ele. Assim,

[...] não é por levar a sério a magia que sua enquete me desagrada. É por ela tratar os termos arte e magia numa acepção tão vaga que acaba tornando impossível uma reflexão séria a respeito dela [...]. Em vez de circunscrever os termos e partir de uma definição possível, por exemplo, a de magia como um conjunto de operações e de crenças que atribuem a certos atos humanos o mesmo valor que a causas naturais [...] o senhor dá aos termos arte e magia o mais fraco valor semântico, isto é, coloca-os num nível em que o sentido se dissipa (Breton, 2008: 123).

Tal declaração causou impacto e marcou por muito tempo, em Paris, as relações que poderiam ser estabelecidas entre a antropologia social e o mundo 
da arte. Tratava-se, na época, para uma etnologia que mal começava a se afirmar, de enfrentar a estética "primitivista". As vanguardas literárias e artísticas, ao se apaixonarem pelas artes "primitivas", guardavam, na realidade, uma grande desconfiança em relação a qualquer abordagem antropológica da arte. Segundo a estética primitivista, que postulava a universalidade da linguagem da arte, qualquer objeto podia ser compreendido independentemente do significado que recebia na sociedade na qual ele havia sido concebido. Breton, que, em resposta às observações de Lévi-Strauss, denunciava "a intolerância e a arrogância de uma etnologia hoje militante, que se acha no dever de defender o que ela considera como seu patrimônio exclusivo" (Breton, 2008: 121), não era o único a defender essa ideia. O exemplo dessa orgulhosa ignorância viera do próprio Pablo Picasso ao declarar: "Não sei nada das esculturas africanas da minha coleção: olho para elas e sei tudo o que é preciso saber". No século XIX, o etnocentrismo ocidental tinha questionado seriamente a universalidade da arte. Na época das vanguardas, o "primitivismo" admitia a existência de uma arte universal, mas recusava levar sua análise mais adiante. Num como no outro caso, a antropologia da arte não tinha lugar.

A paixão, quase cólera, que vibra na resposta de Lévi-Strauss a Breton que, por seu lado, deplorava o espantoso "mau humor" (Breton, 2008: 120) do etnólogo, não decorre apenas das circunstâncias de uma polêmica pessoal. Com certeza ela lembra as críticas que o grande antropólogo formulava, na mesma época, contra os que, como Roger Caillois, "preferiam o estilo à análise" no estudo dos fatos sociais. Mas ela revela também certas raízes do projeto de Lévi-Strauss, para quem a reflexão sobre a arte sempre foi um objetivo essencial. Em Tristes trópicos, por exemplo, o estudo dos grafismos kadiwéu é, para Lévi-Strauss, a ocasião de definir um conceito de estilo que amplia muitíssimo o desafio da análise das formas. Assim, observa ele, o conjunto dos hábitos de um povo "é sempre marcado por um estilo" e é pelo estilo que se pode reconhecer que esses costumes formam sistemas. "Estou convencido" - escreve ele - "de que esses sistemas não existem em número ilimitado, e que as sociedades, como os indivíduos, em seus jogos, sonhos ou delírios, não criam nunca de modo absoluto, mas se limitam a escolher certas combinações num repertório ideal que seria possível reconstituir" (Lévi-Strauss, 1975:183).

Ao fazer o inventário de todos os costumes observados pelos etnólogos, mas também:

de todos os que são imaginados nos mitos, ou evocados nos jogos de crianças e adultos, nos sonhos dos indivíduos sadios ou doentes e nas condutas psicopatológicas, seria possível fazer uma espécie de tabela periódica como aquela dos elementos químicos, na qual todos os costumes reais ou simplesmente possíveis aparecessem agrupados em famílias, e nos quais só tivéssemos que reconhecer os costumes que as sociedades efetivamente adotaram (Lévi-Strauss, 1975: 183). 
O desafio da universalidade da arte como lugar de exploração do pensamento formal foi assim lançado: se a análise estrutural for conduzida corretamente, o estudo de uma máscara ameríndia poderá fazer surgir elementos abstratos aplicáveis a outras manifestações artísticas, e por isso também à obra de um artista ocidental, quer seja um retrato de Clouet, um quadro histórico de Greuze, uma tela de Poussin ou a obra de um artista contemporâneo. LéviStrauss admite que toda arte está ligada à emoção estética. Admite também que essa experiência pode ser universal. Mas a experiência da arte permanece, a seus olhos, misteriosa: o que será que torna eficaz uma obra, por que esse sentimento de admiração e esse prazer que associamos à percepção de certas obras? O ponto de partida dessa reflexão é o Retrato de Elisabeth da Áustria, de François Clouet [ver figura 1]. "Olhemos para esse retrato" - escreve Lévi-Strauss - "e indaguemos quais os motivos da emoção estética tão profunda que nele suscita inexplicavelmente a reprodução, fio por fio, num escrupuloso trompe-l'œil, de uma gola de renda" (Lévi-Strauss, 2008: 582-587).

Percebe-se que a resposta do antropólogo não se refere de modo algum à personalidade do pintor. Ela não mobiliza uma poética específica do artista, nem uma análise do estilo pictórico. Visa, ao contrário, um aspecto esquecido da representação pela imagem: a redução de escala. A gola pintada por Clouet é "como os jardins japoneses, como as miniaturas de carros e os barcos construídos em garrafas, o que, na linguagem dos bricoleurs, se chama 'modelo reduzido'" (Lévi-Strauss, 1962: 34). O quadro de Clouet mostra, de maneira extraordinariamente fiel, um modelo reduzido do mundo. Lévi-Strauss pergunta então "se o modelo reduzido, que é também a 'obra-prima' do companheiro de ofício, não equivale, sempre e em toda parte, à típica obra de arte. Pois parece que todo modelo reduzido tem vocação estética e, inversamente, que a imensa maioria das obras de arte são modelos reduzidos" (Lévi-Strauss, 2008: 583). Para conhecer um objeto real em sua totalidade, nossa tendência, observa LéviStrauss, é proceder começando por suas partes. A resistência que o objeto nos opõe é superada se for dividida. A redução de escala inverte essa situação: de uma imagem como o Retrato de Elisabeth da Áustria apreendemos a totalidade antes de compreender as partes. Com apenas um olhar, dominamos o conjunto de uma representação antes de compreender os elementos que lhe compõem o funcionamento: "menor, a totalidade do objeto parece menos temível; por estar quantitativamente diminuída, ela parece qualitativamente simplificada. Ou melhor, essa transposição quantitativa aumenta e diversifica nosso poder sobre um homólogo da coisa; por meio dele, esta pode ser percebida, sopesada, apreendida numa única olhada" (Lévi-Strauss, 2008: 585).

Esse modelo reduzido do mundo tem outra característica: é explicitamente construído. É feito pela "mão do homem". Logo, não é - prossegue LéviStrauss - "uma simples projeção, um modelo passivo do objeto; constitui uma 


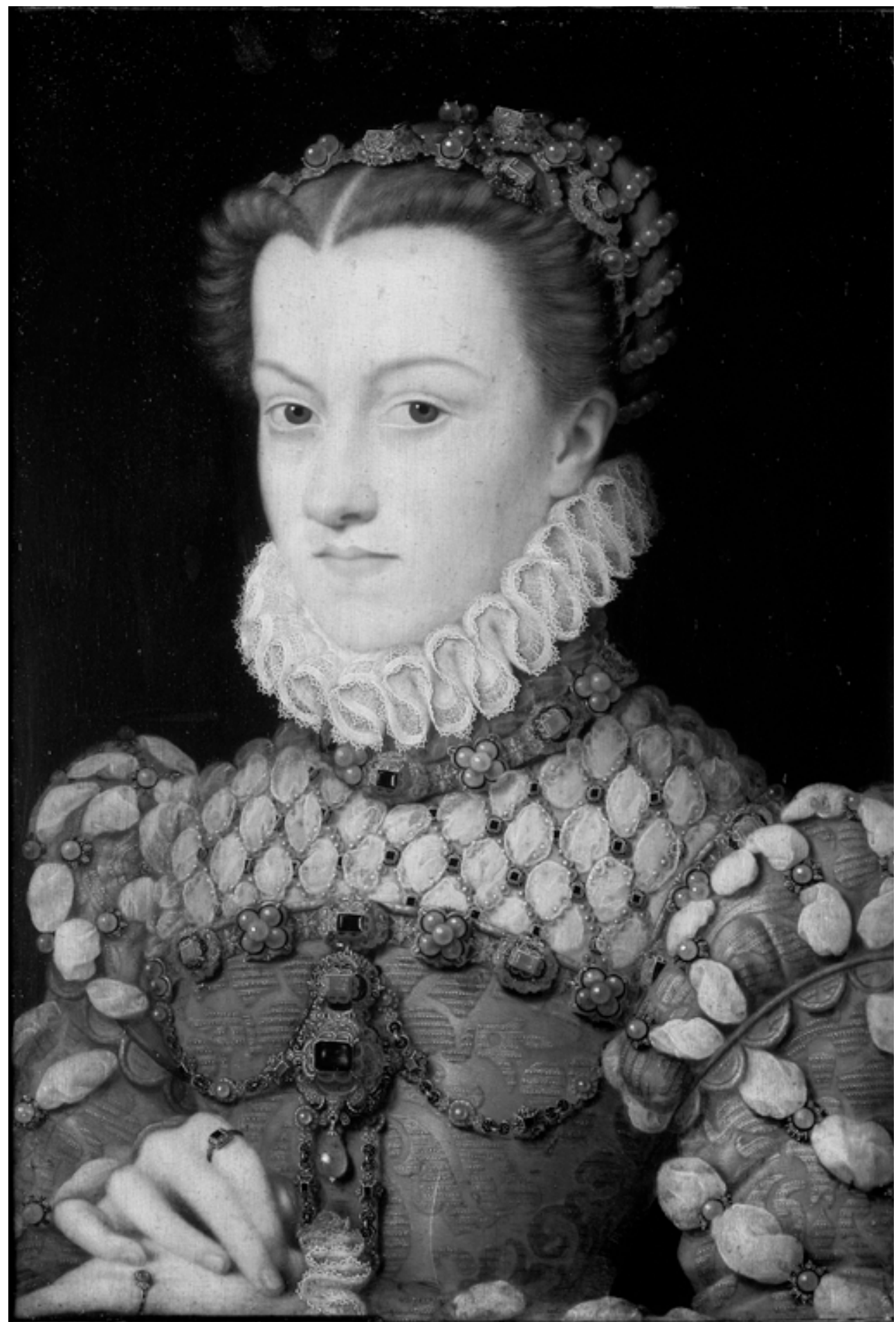

Figura 1: François Clouet, Retrato de Elisabeth da Áustria. O desenho preparatório data de 1571. 
verdadeira experiência sobre o objeto". Essa dupla abordagem (a redução de escala e o tipo de apreensão que ela implica, a experiência de certo poder sobre o objeto construído) permite explicar o poder atribuído à representação plástica, e a tentação, sempre latente, de lhe atribuir uma subjetividade. É graças a esse processo que, conclui Lévi-Strauss: "A boneca da criança já não é um adversário, um rival, nem mesmo um interlocutor; nela e por ela, a pessoa se transforma em sujeito" (Lévi-Strauss, 2008: 585).

Podemos, portanto, perceber melhor o que pode ser, sob esse aspecto, a "magia" de uma obra de arte. Trata-se de um processo específico de interpretação da imagem que leva à formação de uma subjetividade. Tal processo pode tocar, seja o observador que se constrói "como pessoa" diante da representação, e "da qual ele se sente confusamente criador com mais pertinência que o próprio criador" (Lévi-Strauss, 2008: 586), seja a própria representação, que aparece então como um agente potencialmente ativo, dotado de subjetividade própria. Estatueta, desenho ou pintura, a obra de arte pode assim adquirir personalidade próxima daquela de um ser humano. Conclui-se que a ideia de uma "vida" associada à imagem não é uma simples crença exótica, vinda de países longínquos ou primitivos. Pelo contrário, é uma das raízes universais da experiência estética.

O teórico de A arte mágica (embora hesitante, atormentado a ponto de pedir, para redigir seu ensaio, a ajuda de um coautor, a quem se deve, sem dúvida, certas partes do texto $)^{1}$ formulava a hipótese da existência de uma consciência lírica universal, que supostamente permitia um contato intuitivo imediato com todo objeto de arte. $\mathrm{O}$ autor de $\mathrm{O}$ pensamento selvagem propõe, ao contrário, interpretar paralelamente, no interior de cada universo cultural, as coordenadas constitutivas da imagem $e$ as operações mentais que essas coordenadas implicam. Em lugar do olhar imediato, apelando para um lirismo sem análise, do conhecedor primitivista, Lévi-Strauss propõe, portanto, avaliar, para cada invenção de imagem, a operação mental que ela implica. Em vez de buscar, como fizeram Carl Einstein, Braque, Picasso ou Juan Gris, "obras-primas de arte cubistas nos trabalhos plásticos africanos" (Einstein [1915] apud Rowell, 1986: 347), Lévi-Strauss queria mostrar que o que é verdadeiro num ídolo africano ou numa maça polinésica pode também esclarecer, de maneira inesperada, a arte europeia. Uma inversão de perspectiva, cuja repercussão se conhece hoje, tornava-se assim possível.

Poderia se fazer a objeção de que esse modelo de explicação, que se pretende universal, está baseado na imitação da natureza e que este não pode ser aplicado a uma arte que, como grande parte da arte do século XX, visa à abstração. É sabido que Lévi-Strauss se pronunciou em termos contundentes contra toda "pintura não-figurativa", que julgava "acadêmica" e condenada à "representação realista de modelos não existentes" (Lévi-Strauss, 2008: 593). Tal afirmação pode ser vista, hoje, como uma maneira de suprimir o problema em vez de resolvê-lo, ainda mais porque muitas tradições iconográficas não 
ocidentais se baseiam em princípios muito diferentes da imitação da natureza. O problema da representação "abstrata" não é, portanto, específico da arte moderna, nem reservado à tradição ocidental. Fiquemos, por enquanto, na área da arte ocidental, e vamos prosseguir nesse caminho. Como imaginar a "magia" de uma arte abstrata? Qual constituição de subjetividade ela torna possível? De qual universo pode ela ser o "modelo reduzido"? Consideremos o Quadro com arqueiro, de Kandinsky, datado de 1909 [ver figura 2].

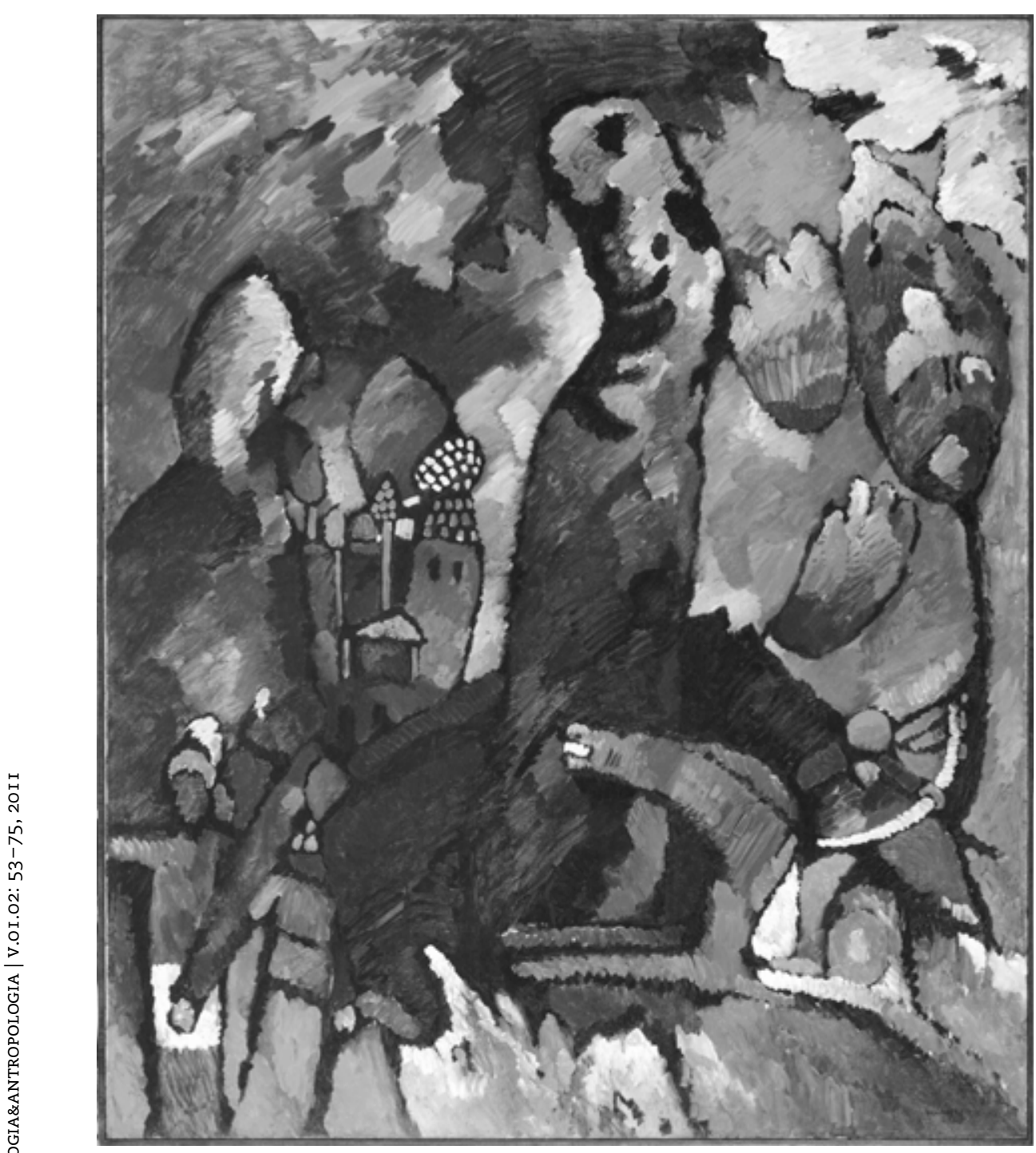

Figura 2: Wassily Kandinky, Quadro com arqueiro, 1909. 
É uma das obras que marcaram uma etapa essencial no nascimento da arte abstrata. A partir dos anos 1910 (quando aparecem as Improvisações abstratas e o primeiro texto que lhe define a poética, Le spirituel dans l'art [Do espiritual na arte], Kandinsky, 1970), o objeto da representação pictórica, na obra de Kandinsky e de alguns companheiros do grupo Der Blaue Reiter [O Cavaleiro Azul], passa por uma transformação radical. O modelo do pintor já não é o mundo externo do qual o artista deve restituir com habilidade um modelo reduzido. Vinte anos antes de Le spirituel dans l'art [Do espiritual na arte], outro livro de artista, Das Problem der Form [O problema da forma], de Adolf von Hildebrand (1893), já enunciara o princípio dessa mudança de objeto, que vai progressivamente ter um papel crucial na arte da modernidade. Toda percepção de espaço e movimento, escrevia Hildebrand, supõe uma experiência da forma. Diante dessa experiência, que orienta nossa interpretação das obras de arte, o tema da obra tem um papel menos importante. Uma natureza morta de Chardin, representando objetos banais colocados num canto do ateliê, pode tornar-se (sobretudo a partir do último período de vida do artista) uma imagem intensamente trágica. O tema da tela torna-se, no caso, quase inútil para a experiência estética. É o espaço (a experiência da luz, da relação entre superfície e volume, e o movimento implícito que anima, ou que, ao contrário, marca com estranha imobilidade, os objetos) que decide a natureza da representação. Kandinsky e seus companheiros de percurso propõem, desde 1910, um desenvolvimento radical dessa interpretação da experiência estética (que teve, aliás, um papel-chave na formação do gosto dos primitivistas). Resumo de sua lógica: se o que conta numa obra de arte não é o tema, mas a experiência da forma que ela implica, por que não imaginar uma arte que tomaria essa experiência mesma como "tema" da representação? Para a arte "espiritual" (termo, para ele, sinônimo de "abstrato") que Kandinsky defende, o mundo já não é o tema da representação. O que o artista deve visar, deixando de lado as aparências, é o ato mental que a percepção do mundo supõe. Se a obra, "como um jardim japonês", no dizer de Lévi-Strauss, deve restituir um "modelo reduzido" do mundo, será, portanto, um modelo desse espaço interior que ela tentará, com seus próprios meios (linha, superfície, cor, luz) recompor. Como essa passagem para uma "arte sem imagem" se efetua na obra que escolhemos, em termos estritamente visuais?

Comecemos por uma constatação. No Quadro com arqueiro (e mais ainda nas Improvisações abstratas que se seguem), Kandinsky efetua uma inversão da função tradicional da cor. No Retrato de mulher de Clouet, a cor ainda anima (segundo uma das possibilidades do modelo estético tradicional) um espaço da representação essencialmente definido pelo desenho. "A figuração de uma gola de renda em modelo reduzido" - observava Lévi-Strauss - "implica um conhecimento interno de sua morfologia e de sua técnica de fabricação, não se reduz a um diagrama ou a uma prancha de tecnologia. Ela realiza a síntese dessas propriedades intrínsecas e das que derivam de um contexto espacial e temporal" (Lévi-Strauss, 2008: 586). 
No interior dessa síntese, é o desenho, o diagrama do objeto, que mostra ao mesmo tempo "a gola tal como ela é" e a gola "tal como, no mesmo instante, sua aparência é afetada pela perspectiva na qual ela se apresenta" (Lévi-Strauss, 2008: 587). No Quadro com arqueiro, de Kandinsky, essa função essencial do desenho é questionada. Os ritmos que regem a percepção da paisagem, aqui expressos em termos essencialmente cromáticos, investem de tal maneira o tema da representação (o cavaleiro, seu arco, seu cavalo, sua montaria ornamentada) que o equilíbrio tradicional entre a forma e o fundo da imagem se inverte. É o fundo, a experiência visual de uma superfície decomposta pela luz, que domina a forma, e, por isso, o tema que se apresenta.

Na reflexão teórica de Kandinsky, o conceito de forma tem duplo valor. Enquanto se opõe à cor, ela representa, em Ponto e linha sobre plano, assim como em suas aulas no Bauhaus (Kandinsky, 1970), um meio visual específico da representação. A linha separa, sublinha, distingue. O conceito de forma implica, dessa perspectiva, a "delimitação" como operação mental. Logo, normalmente é a demarcação de um contorno que assume o papel de motor da percepção do espaço e do equilíbrio dinâmico que se estabelece entre a forma e o fundo. Mas, quando ela se opõe ao conteúdo, a forma também designa, para Kandinsky que se junta assim à linguagem e ao pensamento de Hildebrand -, o conjunto da experiência estética do espaço e do movimento. Ora, o Quadro com arqueiro mobiliza simultaneamente esses dois possíveis sentidos da noção de forma. Por um lado, é evidente que quase nada já distingue os dois planos, o do arqueiro a cavalo e o da paisagem que o cerca. Uma espécie de hipótese implícita de indistinção entre a paisagem e o tema marca aqui a natureza do espaço. Luz e cor dominam. O cavaleiro carregando um arco torna-se tão difícil de distinguir que quase se pode dizer que apenas o título assinala a sua presença.

Por outro lado, o fundo cromático, que domina a percepção da obra, desempenha aqui plenamente o papel de forma, pois constitui o verdadeiro suporte da experiência estética do espaço. Esse quadro que parece, à primeira vista, quase "sem objeto", é de fato determinado por uma inversão de suas coordenadas constitutivas. É a cor (e não o desenho, como "demarcação de um contorno") que tem o papel de revelador da forma: como espaço, movimento e luz. O Quadro com arqueiro é, portanto, uma obra "abstrata" não porque se refere a um "real inexistente", mas porque o tema representado só se encontra evocado como um episódio, um "conteúdo" sem pertinência direta para a percepção da obra. No ponto em que se quer ver apenas um vazio, uma falta de referência à natureza, encontra-se uma reflexão sobre o olhar. Esse processo de geração de um espaço, ao mesmo tempo indissociável da cor e marcado pela introdução de formas convencionais, que aí se esboça, vai desenvolver-se cada vez mais, segundo essa mesma lógica, na grande série das Improvisações.

Naturalmente, Breton estava longe de ignorar a importância da obra de Kandinsky. Em A arte mágica, ele reconhecia até que "é sob a dupla invocação de 
De Chirico e do mestre das Improvisações abstratas que se desenvolveu quase toda a pintura de valor no século XX" (Breton, 2008: 105). O fundador do Surrealismo, que havia enviado em 1933 ao mestre da abstração um "convite de honra" para que ele fizesse parte do movimento, ao expor no Salon des Surindépendants [Salão dos Superindependentes] (Breton, 2008: 105, 1231), acrescentava que a arte de Kandinsky "proveniente da sombria Sibéria onde se confundem a demonologia hiperboreal, os ideogramas chineses e os rudimentos da arte das estepes [...] fechava o círculo da atividade estética com seus suntuosos acordes bárbaros" (Breton, 2008:105).

De fato, a verdadeira revolução refere-se aqui, antes mesmo do estilo ou da personalidade do artista, por um lado, à relação que se estabelece entre duas noções técnicas da arte pictórica (desenho e cor), e, por outro lado, ao status do próprio tema da representação, que passa do modelo reduzido do mundo para a experiência da forma como fato a representar. Mais ligado à interação dos elementos constitutivos da obra do que à paráfrase da linguagem do esoterismo, esse nível de análise se aproxima da definição do universo de discurso próprio da representação icônica. Em Regarder, écouter, lire [Olhar, escutar, ler] (2008), Lévi-Strauss observou que, do ponto de vista do antropólogo, a diferença entre a arte do Ocidente e as chamadas artes "primitivas" não se refere, em primeiro lugar, nem à evolução das técnicas, nem à diferença de estilo, nem mesmo à existência, sobre a qual tanto se falou, da pessoa do artista. Ela concerne ao mesmo tema que teve papel crucial (embora em sua perspectiva pessoal de trabalho e segundo seus próprios termos) na reflexão de Kandinsky: a natureza do modelo representado por meio da obra.

É possível falar de arte "primitiva" em dois sentidos. Ou porque a insuficiência de savoirfaire e de meios técnicos impede o artista de atingir o fim que ele se propõe - imitar o modelo - e só lhe permite significá-lo. Seria o caso da arte chamada "art naï". Ou porque o modelo presente no espírito do artista, por ser sobrenatural, escapa por essência aos meios sensíveis de representação: por excesso de objeto e não por defeito do sujeito, o artista só poderá, também nesse caso, significar. Sob modalidades diversas, a arte dos povos sem escrita ilustra este último caso (Lévi-Strauss, 2008: 154).

Vamos retomar e desenvolver esse ponto. Mas, convém ainda lembrar que, num texto memorável de La voie des masques [A via das máscaras], LéviStrauss observa que o estudo dos objetos pode também ser conduzido sob um novo ponto de vista que procura, mais do que os objetos considerados singularmente, a maneira como eles são classificados pelas culturas e as relações que se podem estabelecer entre eles. Nessa perspectiva, o objeto da análise será composto não apenas daquilo que é materialmente realizado como obra, mas também daquilo que poderia ter sido e daquilo que está excluído do universo das obras possíveis. 


\begin{abstract}
Seria ilusório imaginar, como tantos etnólogos e historiadores da arte fazem até hoje, que uma máscara e, de modo mais geral, uma escultura ou um quadro, possam ser interpretados cada um apenas por si, pelo que representam ou pelo uso estético ou ritual aos quais se destinam. Vimos, ao contrário, que uma máscara não existe em si; ela supõe, sempre presente a seu lado, outras máscaras reais ou possíveis [...] uma máscara não é o que ela representa, mas o que ela transforma, isto é, o que ela escolhe não representar (Lévi-Strauss, 1975: 116-117).
\end{abstract}

Tal intuição, que pode parecer surpreendente, é apenas o desenvolvimento da análise de Boas, e, por trás dela, toda a tradição da biologia das imagens, de Pitt Rivers a Stolpe (Severi, 2007). Ela retoma também certas reflexões de 0 pensamento selvagem, em que Lévi-Strauss escrevia que o problema apresentado por um artista em sua obra

sempre comporta várias soluções. Como a escolha de uma solução comporta uma modificação do resultado ao qual outra solução teria levado, é, portanto, o quadro geral dessas permutas que se encontra virtualmente dado, ao mesmo tempo que a solução particular oferecida ao olhar do espectador, transformado por esse fato - sem mesmo que ele o saiba - em agente. Pela mera contemplação, o espectador é, por assim dizer, remetido a outras modalidades possíveis da mesma obra, [...] a melhor título que o próprio criador, que as abandonou excluindo-as de sua criação (Lévi-Strauss, 2008: 585-586).

"Essas modalidades formam perspectivas suplementares" - prossegue ele - "abertas a partir da obra atualizada. Ou seja, a virtude intrínseca do modelo reduzido é que ele compensa a renúncia a dimensões sensíveis pela aquisição de dimensões inteligíveis" (Lévi-Strauss, 2008: 585). Tais dimensões inteligíveis, que constituem aspectos latentes das obras, abrem para LéviStrauss, "uma imensa extensão" na qual "crenças míticas, práticas rituais e obras permanecem solidárias umas das outras quando se imitam e, até, talvez sobretudo, quando parecem se atribuir desmentidos" (Lévi-Strauss, 2008: 981). Essa "imensa extensão", concebida "em escala de milênios" dentro do espaço cultural da Costa Noroeste, constitui, como se sabe, o objeto da demonstração de A via das máscaras. Mas continuemos ainda na tradição artística ocidental, na qual essa perspectiva permite esboçar uma nova abordagem de análise. As Notes sur l'Olympia de Manet [Notas sobre a Olympia de Manet], que acabam de ser publicadas (Lévi-Strauss, 2008: 1671), autorizam formular com clareza essa abordagem. Trata-se de, em vez de "tentar situar uma obra na filiação histórica de outra", de "comparar tentativas paralelas para dar a problemas lógicos uma expressão plástica" e com elas estabelecer séries ordenadas.

Retomemos, desse ponto de vista, nossa análise do Quadro com arqueiro, de Kandinsky. Essa obra oferecia dois problemas visuais. Tratava-se, de um lado, de inventar um espaço onde a cor pudesse ter o papel da forma, e, por outro lado, assim estabelecer um novo equilíbrio, quase uma identificação, entre a forma e o fundo. Esses dois problemas apresentam certa relação entre o espaço e a cor. A obra de Kandinsky oferece, como acabamos de ver, uma solução original. 
Mas, dentro de qual série, mais fundada na comparação das soluções plásticas do que na cronologia, será possível inserir esta obra? Como avaliar, além do que o Quadro com arqueiro representa, também aquilo que ele transforma? Como compreender o que Kandinsky, como um criador de máscaras da Costa Noroeste, "replica a outros criadores passados ou presentes, atuais ou virtuais" (Lévi-Strauss, 2008: 981)?

William Turner expôs na Royal Academy de Londres, em 1843, duas paisagens diretamente inspiradas pela Teoria das cores, de Goethe, em que aparece o problema da relação entre o espaço e a luz. Cada quadro tem duplo título: um descreve o "tema" pelo qual se pode interpretar a imagem. O outro contém um comentário sobre a relação que se estabelece entre a luz e a cor. Trata-se de Sombra e trevas (A noite do Dilúvio) e Luz e cor (O dia seguinte ao Dilúvio) [ver figuras 3 e 4]. A referência à obra de Goethe é aqui direta e intencional. Turner se refere em particular a um trecho em que Goethe opõe as cores quentes (amarelo, laranja e vermelho, que ele marca com o sinal mais) às cores frias (azul, azul esverdeado e violeta, que ele marca com o sinal menos). Segundo Goethe, as cores quentes geram "sentimentos vivos, alegres, decididos", ao passo que as outras provocam impressões "agitadas, desconfiadas, atormentadas" (apud Gowing, 1994: 98-99). Goethe completava essa primeira oposição com uma série de outros contrastes, de tipo físico, químico ou psicológico:

\begin{tabular}{l|l} 
Mais & Menos \\
\hline Amarelo & Azul \\
\hline Ação & Negação \\
\hline Luz & Sombra \\
\hline Brilho & Escuridão \\
\hline Força & Fraqueza \\
\hline Calor & Frio \\
\hline Proximidade & Distância \\
\hline Repulsa & Atração \\
\hline Afinidades com os ácidos & Afinidade com as bases
\end{tabular}

É fácil ver que nas duas "pinturas do Dilúvio" Turner privilegia, dessas oposições, as que se podem traduzir em indicações de espaço. Nas duas composições, em que as indicações gráficas estão reduzidas ao mínimo - percebe-se 
66

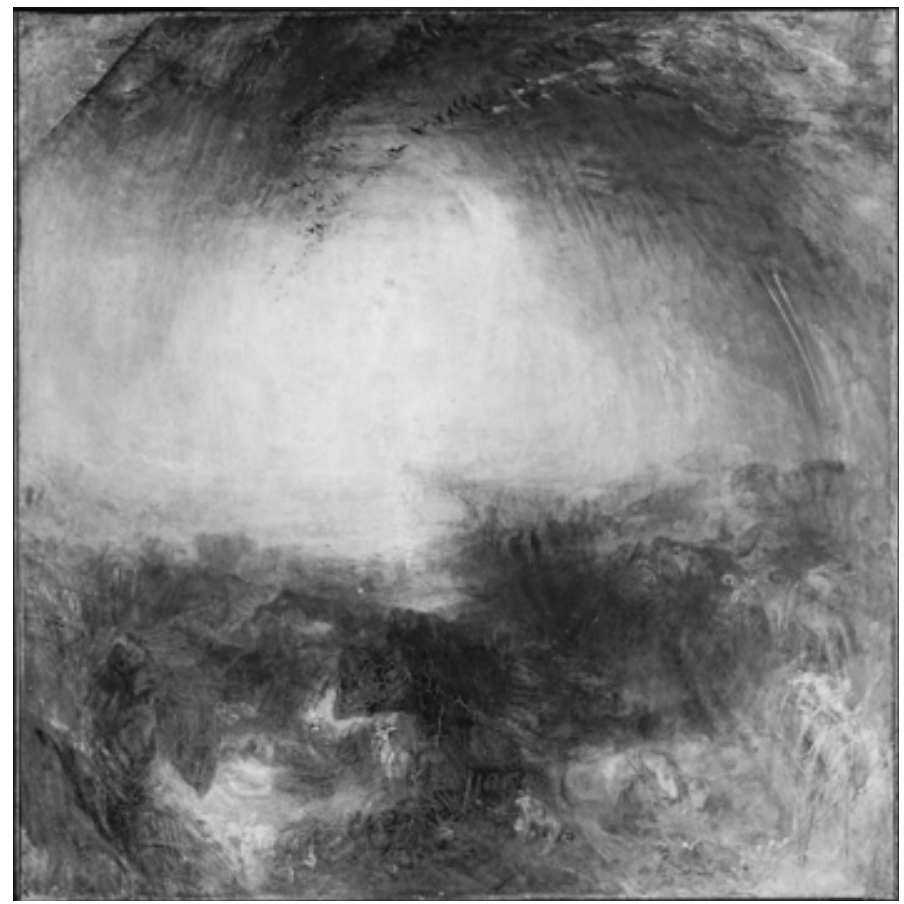

Figura 3: William Turner, Sombra e trevas (A noite do Dilúvio), 1843.

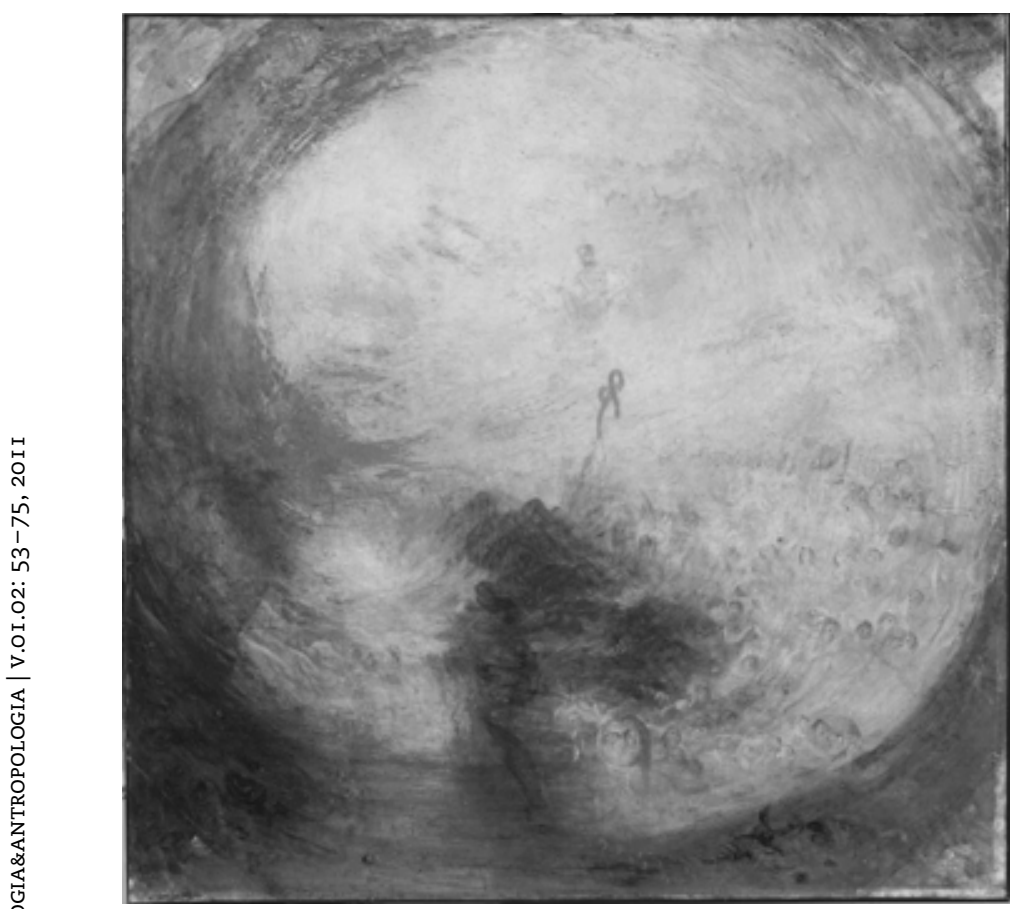

Figura 4: William Turner, Luz e cor (O dia seguinte ao Dilúvio), 1843. 
que nem existe a indicação de um horizonte - o sombrio das cores frias marca a distância, ao passo que o brilho da cor quente marca, para o observador, a proximidade. A atração exercida pelos azuis, verdes e pelo preto, que leva o olhar para o fundo da cena do dilúvio, opõe-se ao deslumbramento (e, portanto, ao brilho, fruto de proximidade e de calor) que emana das partes mais luminosas do quadro. Turner "segue" aqui a teoria de Goethe, mas serve-se dela para formular um problema específico, que o preocupou toda a vida: como compreender (e, portanto, reproduzir) as condições "nas quais a luz refletida se torna imagem" (Gowing, 1994: 39)? Trata-se, para ele, de imaginar um espaço esférico, onde indicações inscritas numa superfície plana se tornem indicações de profundidade, utilizando quase exclusivamente a cor. O método de Turner, ao mesmo tempo original e profundamente apoiado em Goethe, consiste em jogar com a influência recíproca de cores primárias para que a nuança desejada se produza não sobre o quadro, mas diretamente no olho do observador. Em vez de misturar as cores para obter nuanças, Turner aplica no papel ou na tela toques mínimos de cores primárias (“fine dots of primary colours") (Finley, 1967: 366-367), deixando que o olhar faça a síntese. Logo, já não é a técnica do artista que vai produzir todas as cores. É o olhar do observador que, seguindo a "polarização" (fenômeno que Goethe definira como a influência recíproca das cores em situação de contraste simultâneo), vai gerar, pelo menos em parte, as cores secundárias.

A descoberta desse método, que fascinou e escandalizou seus contemporâneos, fez de Turner um precursor reconhecido tanto por Seurat e pelo movimento dos Divisionistas quanto pelos pintores da abstração norte-americana dos anos 1950 (Motherwell, 1999). Convém acrescentar que esse método não se refere apenas aos efeitos cromáticos. Pela luz, é todo o espaço da paisagem que fica assim orientado. Como observou Gowing, nos dois quadros inspirados por Goethe, que se organizam num espaço quase esférico, "vemos deslocar-se o foco da imagem" a ponto de ele se afastar com força do centro da tela (Gowing, 1994: 98). Uma comparação com outras composições circulares ajuda-nos a especificar esse ponto essencial. Consideremos duas obras de Gottfried Wals, Paisagem romana com figuras e Estrada rural ao lado de uma casa [ver figura 5], pintor alemão que trabalhou em Roma no início do século XVII e que foi especialista nesse tipo de composição.

Wals tenta nessas paisagens uma composição que, do ponto de vista da concepção do espaço, não está longe do projeto de Turner. É evidente que nas paisagens de Wals, a estrutura do espaço - preenchido pelas ruínas de Roma num caso, muitíssimo despojado no outro - faz referência explícita à esfera. O contraste entre sombra e luz, nessas obras em que o uso da cor é constantemente vigiado, adota aqui uma organização linear singularmente estrita. Para que haja profundidade, é preciso que o ponto de fuga em torno do qual se organiza a perspectiva, entre em tensão com o centro da tela. Não deve coincidir, nem se colocar muito longe do centro, já que, em ambos os casos, o efeito de 


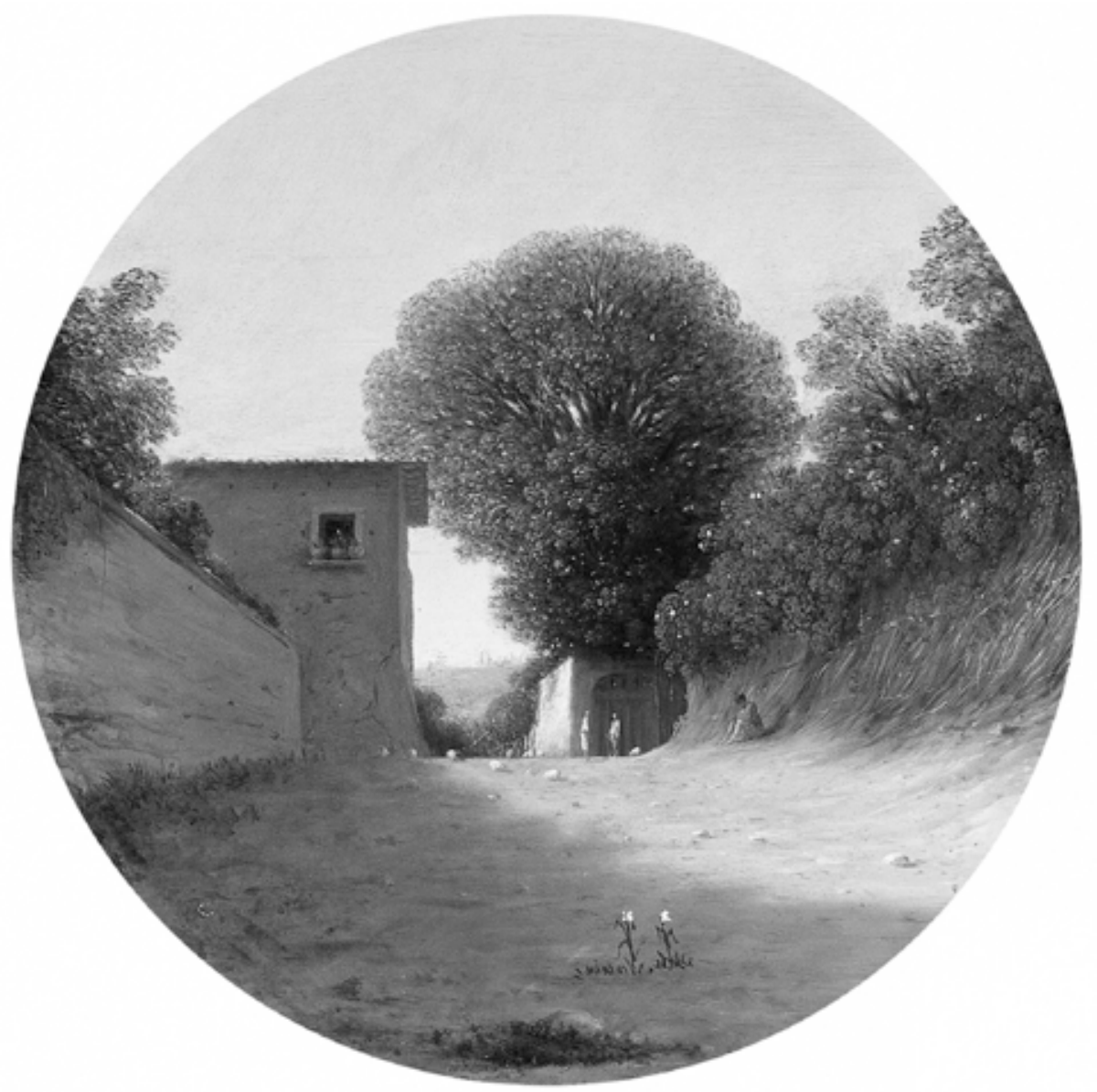

Figura 5: Gottfried Wals, Estrada rural ao lado de uma casa, c. 1619-1620.

profundidade se perderia. A organização circular da composição permite, por meio dessa distância entre centro real da tela e ponto de fuga da composição, uma visão de imersão que intensifica a impressão de profundidade. Nesse tipo de composição, os dois fatores operam juntos para que o observador possa aceder ao espaço e projetar-se para o horizonte. Tal proeza técnica não é, em Wals (como em Turner), gratuita. Implica provavelmente uma meditação sobre a própria pintura, sobre seu aspecto tão ilusório quanto perfeito. Num espírito bem próximo do Barroco, a relação que se estabelece entre a perfeição técnica da representação e seu aspecto provisório - mais especificamente ainda quando, como em Estrada rural ao lado de uma casa, a composição parece sem tema -, o que está em jogo é a vaidade das aparências e a angústia que pode pesar sobre elas. Quanto mais perfeita é a técnica, mais o caráter fictício (e, portanto, frágil) da representação se torna sensível. 
Turner trabalha em sentido rigorosamente inverso: naquilo em que Wals, calculando rigorosamente a distância entre ponto de fuga e centro do círculo, busca a ilusão de profundidade, Turner deseja representar, sobretudo em Luz e cor, um deslumbramento, uma irrupção súbita da luz, que se projeta para fora num espaço curvo, quase convexo. Naquilo em que Wals estabelecia uma relação entre visão imergente e percepção da profundidade utilizando recursos gráficos, Turner constrói apenas pelo contraste entre cores quentes e frias, brilhantes e sombrias, próximas e afastadas. Pela justaposição de cores negativas e positivas, Turner não busca apenas a profundidade: procura atingir uma espécie de iminência do espaço, uma intensificação da visão próxima da vertigem.

Como "solução possível" para um problema visual, é claro que o Quadro com arqueiro de Kandinsky poderia ser facilmente inserido numa série na qual as duas pinturas de Turner constituiriam um primeiro termo. Independente de qualquer cronologia, essa série seria idealmente formada de soluções oferecidas, por um lado, ao problema da construção do espaço por meio do uso da cor, e, por outro lado, à ideia de uma representação direta da experiência visual como sujeito (declarado até no título das obras de Turner) da obra. Seria possível, se os limites deste artigo permitissem, enriquecer essa série, orientada pelas dimensões lógicas dos problemas visuais, com outras obras e outros autores. Mas voltemos ainda à obra de Kandinsky. Admitindo-se que ela se inscreva numa série que a aproxime, independentemente das influências que um artista possa ter sobre outro, de certas pesquisas de Turner, que consequências podem ocorrer? O Quadro com arqueiro mobiliza, já ficou dito, dois problemas visuais: um refere-se à relação entre o objeto e o espaço no qual ele se situa. O outro se refere à construção, pela cor, da experiência da forma. Nos mesmos anos 1910, em Paris e outros lugares da Europa, dois artistas descobriram outras soluções para ambos os problemas. Desde 1913, Mondrian deslocou o tema de suas obras da representação da natureza (árvores, representadas à maneira cubista, paisagens cada vez mais despojadas) para relações que se estabelecem entre os objetos reais ou entre os elementos de uma paisagem. Para ele, como para Kandisnky, tratava-se de representar um processo de pensamento, sem passar pela representação da natureza. Um texto de 1918-1919 expõe de modo bem claro essa passagem: "Antes de escolher a abstração, eu me expressava por meio da natureza [...]. Mais tarde, minha obra mostrou um abandono dos aspectos naturais das coisas e a emergência gradual de uma expressão plástica das relações que se estabelecem no espaço" (Mondrian, 1970). A série de obras intitulada Píer e oceano, cujo exemplo está na Figura 6, desenvolve esse método que consiste em espalhar pelo espaço pictórico indicações de relações (no caso horizontais e verticais) que procuram, por meio da ausência dos termos reais dessas relações, instalar um espaço infinito. 


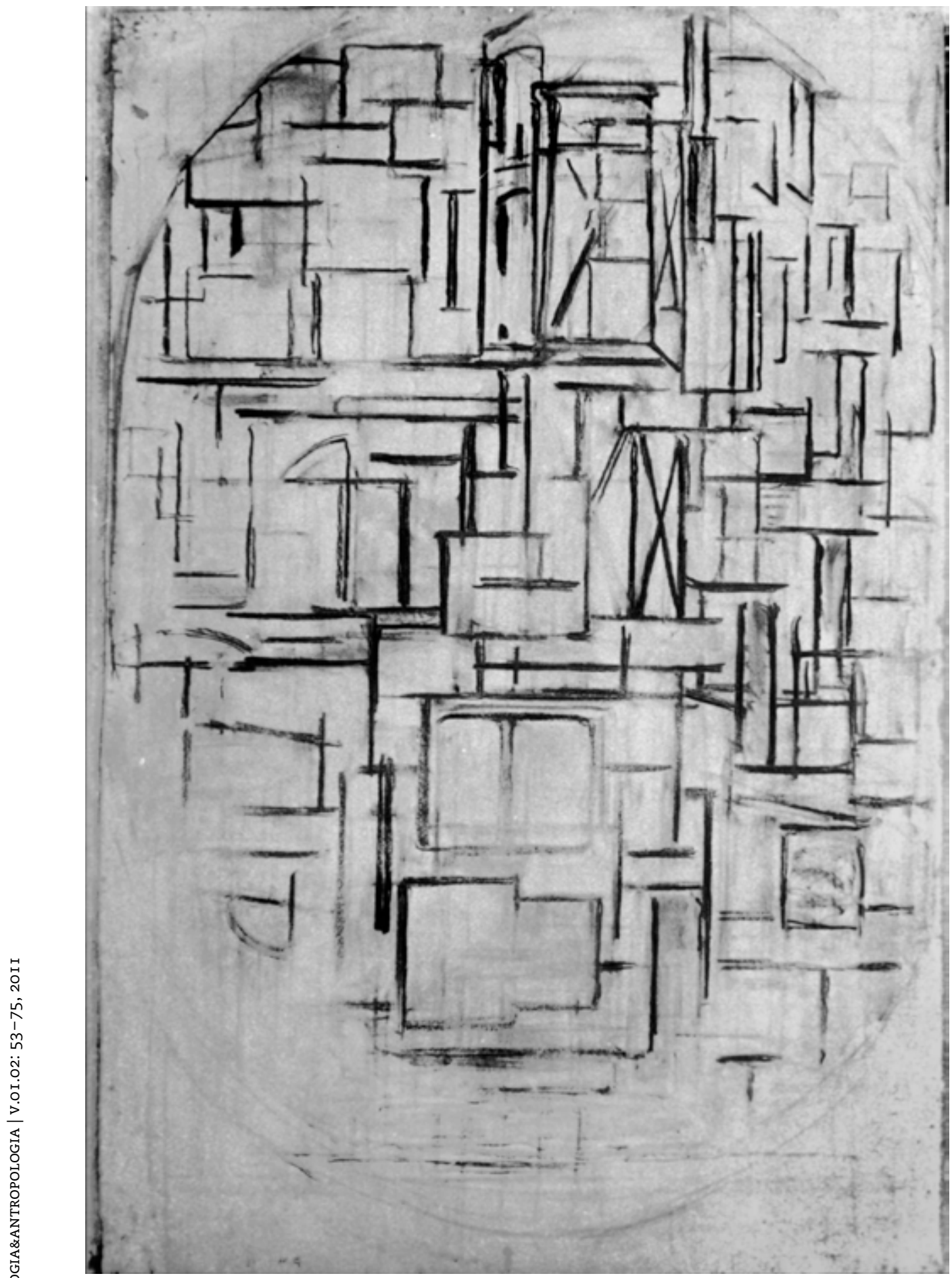

Figura 6: Piet Mondrian, Composição oval sem título, 1914. 
O primeiro problema proposto por Kandinsky, da relação entre forma e fundo, recebe aqui uma solução original. Jogando com a cor como propulsor da experiência do espaço e do movimento, o mestre russo inverteu a relação entre o tema e a paisagem. Indicada de modo implícito por Kandinsky, essa relação se tornou explícita, e até visível, com Mondrian. Ela torna o objeto uma solução plástica, transforma-o em tema da representação.

Nos mesmos anos, no grupo parisiense dos Cubistas, Robert Delaunay buscou uma solução original para o segundo problema apresentado por Kandinsky e longamente estudado por Goethe e Turner: o da instalação de um espaço ilusório com a ajuda do que poderia ser chamado a síntese mental da cor. Liberado de toda figuração, mesmo convencional, seu Disco simultâneo de 1913 (em que se observa outro problema que interessava a Turner: o do espaço esférico) transformou o encontro das cores no interior do próprio olhar em tema do trabalho do artista. Como Albert Gleizes reconheceu quase imediatamente, o Delaunay dos Discos: "[...] só pintava com a cor. Pretendia que, em vez de destruir, a cor construía, edificava a forma [...]" (apud Seuphor, 1949: 28, grifos meus).

Durante esse período (que foi com certeza o mais feliz de seu trabalho como pintor), Delaunay não buscava apenas, como Turner em relação a Goethe, ilustrar uma teoria das cores e da propagação da luz que, no seu caso, era a dos "contrastes simultâneos" de Chevreul (1969). Ele procurava, sobretudo, uma transcrição visual da ideia de simultaneidade. Consideremos o Disco simultâneo, de 1913.

A distinção muito nítida, entre cores frias e cores quentes, que estão distribuídas por regiões no conjunto da obra, se transforma bruscamente, no disco central, num confronto entre dois semicírculos quase monocromáticos, vermelho e azul, de contraste intenso. A distinção entre os quatro eixos que marcam, em sentido horizontal e vertical o conjunto do Disco, até então sublinhada pelas cores, tende assim a desaparecer. No círculo central, por conseguinte, a distinção nítida entre o vermelho e o azul provoca uma dificuldade para perceber a diferença, infinitamente mais leve, entre dois vermelhos e dois azuis pouco diferentes, que marcam duas seções equivalentes dos dois semicírculos. O “contraste simultâneo" implica aqui seu contrário: a sucessão visual de cores quentes e frias, com as consonâncias, as dissonâncias, os jogos de ritmos que ela implica, gera afinal uma imagem central que se desdobra no instante: dois vermelhos e dois azuis se tornam não apenas simultâneos, mas também quase idênticos. Como desejava Turner em suas últimas paisagens, o trabalho do olhar revela-se a si mesmo: a cor se situa tanto no disco como dentro do olho do observador. Como escrevera Goethe, o mundo não possui, em si, cor nenhuma. Só o olhar, e o trabalho do espírito que ele reflete, pode lhe atribuir a cor (Goethe, 2005).

Com Turner, Kandinsky, Mondrian e Delaunay, uma série organizada a respeito do problema da relação entre espaço e cor (e a relação entre forma e 
fundo, que ela implica) parece se esboçar. Delaunay radicalizou o processo de convencionalização das formas que Kandinsky tentara, levando a experiência da forma para uma situação anicônica. Mondrian, por seu lado, aboliu progressivamente a cor e só guardou relações de espaço. Cada um desses artistas, longe de "caminhar sozinho pela via da criação" (Lévi-Strauss, 2008: 981), escolheu um aspecto do problema apresentado por Turner em suas derradeiras experiências com luz e espaço.

Nossa análise leva, portanto, a identificar três princípios antropológicos de inteligibilidade das imagens: o estudo das operações mentais implicadas pela representação icônica (e os processos de "constituição de subjetividade" que essas operações implicam), a definição do universo de discurso que lhe é próprio, e a instalação de séries iconográficas que constituem, segundo a expressão de Lévi-Strauss, soluções visuais para problemas lógicos apresentados.

Esses três princípios constituem apenas o ponto de partida de um programa de trabalho, que somente a interpretação de fatos etnográficos poderá desenvolver. Por enquanto, concluímos que eles podem ser legitimamente aplicados a certos aspectos da arte ocidental, mesmo quando a imitação da natureza, tão cara a Claude Lévi-Strauss, tende a desaparecer.

Artigo recebido para publicação em maio de 2011.

Carlo Severi é diretor de estudos na École des Hautes Études en Sciences Sociales (EHESS), membro do Laboratoire d'Anthropologie Sociale do Collège de France e do departamento de pesquisa do Musée du quai Branly, em Paris. É autor de Naven ou le donner à voir: essai d'interprétation de l'action rituelle (1994), em coautoria com Michael Houseman, e de Le principe de la chimère: une anthropologie de la mémoire (2007). Desenvolve pesquisas sobre, entre outros temas, imagem e memória social. 


\section{NOTA}

1 Trata-se de Gérard Legrand, que, desde 1955, começa a participar da redação do livro. Ver Breton (2008: 1219-1220).

\section{REFERÊNCIAS BIBLIOGRÁFICAS}

Breton, André. L'art magique. In: Euvres. Paris: Gallimard, 2008 (Vol. 4: Ecrits sur l'art).

Chevreul, Michel Eugène. De la loi du contraste simultané des couleurs. Paris: Léonce Laget, [1839] 1969.

Einstein, Carl. Negerplastik. In: Rowell, Margit (org.). Qu'estce que la sculpture moderne? Paris: Centre Georges Pompidou, 1986, p. 344-354.

Kandinsky, Wassily. Tous les écrits. Paris: Dénoël, 1970.

Finley, Gerald E. Turner: an early experiment with colour theory. Journal of the Warburg and Courtauld Institutes, 1967, 30, p. 357-366.

Goethe, Johann Wolfgang von. Traité des couleurs. Paris: Triade Editions, 2005.

Gowing, Lawrence. Turner: Peindre le rien. Paris: Macula, 1994.

Lévi-Strauss, Claude. La pensée sauvage. Paris: Plon, 1962 . La voie des masques. Genebra: Skira, 1975 (2 vol.). . Euvres. Paris: Gallimard (Bibliothèque de la Pléiade), 2008.

Marc, Franz. Les cent aphorismes: la seconde vue. Paris: Fourbis, 1996.

Mondrian, Piet. Dialogue on Plasticism. In: Writings. Nova York: Viking Press, 1970.

Motherwell, Robert. The collected writings of Robert Motherwell. Berkeley/Los Angeles/Londres: University of California Press, 1999.

Rowell, Margit. Qu'est-ce que la sculpture moderne? Paris: Centre Georges Pompidou, 1986.

Seuphor, Michel. L'art abstrait, ses origines, ses premiers maîtres. Paris: Maeght, 1949.

Severi, Carlo. Le principe de la chimère: une anthropologie de la mémoire. Paris: Rue d'Ulm/Musée du quai Branly, 2007. 


\section{OBRAS PLÁSTICAS E CRÉDITOS DAS IMAGENS}

p.58 François Clouet, Retrato de Elisabeth da Áustria (1554-1592). O desenho preparatório data de 1571. Óleo sobre madeira; $36 \mathrm{x}$ $26 \mathrm{~cm}$. Louvre, Paris. @ 2011 Scala, Florença.

p.60 Wassily Kandinsky, Quadro com arqueiro, 1909. Óleo sobre tela; 175 x 144,6 cm. Museu de Arte Moderna (MoMA), Nova York. @ 2011 Digital image, The Museum of Modern Art, Nova York/Scala, Florença.

p.66 William Turner, Sombra e trevas (A noite do Dilúvio), 1843. Óleo sobre tela; 78,5 x $78 \mathrm{~cm}$. Coleção Tate Gallery, Londres. (c) Tate Gallery.

p.66 William Turner, Luz e cor (O dia seguinte ao Dilúvio), 1843. Óleo sobre tela; 78,5 x 78,5 cm. Coleção Tate Gallery, Londres. ()Tate Gallery.

p.68 Gottfried Wals, Uma estrada rural ao lado de uma casa, c. 1619-1620. Óleo sobre cobre; $24,5 \mathrm{~cm}$ (diâmetro). The Fitzwilliam Museum, Cambridge, UK. @The Fitzwilliam Museum

p.70 Piet Mondrian, Composição oval sem título, 1914. Carvão sobre papel; 152,5 x $100 \mathrm{~cm}$. Coleção Peggy Guggenheim, Veneza. (c) 2011 Photo Art Media/Heritage Images/Scala, Florença. 
Palavras-chave: Resumo:

Lévi-Strauss; Arte abstrata; Imagem; Cognição;

Estruturalismo.

Keywords:

Lévi-Strauss; Abstract Art; Image; Cognition; Structuralism.
Neste artigo, parte-se da abordagem teórica da arte por Lévi-Strauss para aplicá-la a um objeto não explorado pelo próprio autor: a arte abstrata no Ocidente. O texto inicia com uma polêmica entre Lévi-Strauss e o teórico do surrealismo, André Breton, em torno da magia da arte. A polêmica põe a nu a originalidade de Lévi-Strauss enquanto teórico da arte, em diálogo permanente com os Modernistas de sua época, assim como a centralidade da arte na sua teoria estruturalista. Se para Breton a magia da arte é universal porque apela para processos de apreensão intuitivas, opostos à razão, para Lévi-Strauss o desafio da universalidade da arte consiste no fato de este ser um dos lugares privilegiados de exploração do pensamento formal. LéviStrauss propõe interpretar paralelamente, no interior de cada universo cultural, as coordenadas constitutivas da imagem e as operações mentais que essas coordenadas implicam. Se Lévi-Strauss seguiu este caminho para dar sentido aos arabescos kadiwéu, propõe-se aqui seguir esta trilha na exploração da arte abstrata.

Abstract:

In this paper, one attempts to apply Lévi-Strauss' theoretical approach to art to an object he himself has not examined: abstract art in the West. The text begins with a controversy between Lévi-Strauss and the theorist of Surrealism, Andre Breton, over the magic of art. The controversy highlights the originality of Lévi-Strauss as a theorist of art, in permanent dialogue with the Modernists of his time, as well as the centrality of art in his structural theory. If for Breton the magic of art is universal because it appeals to processes of intuitive apprehension, opposite to reason, for Lévi-Strauss the challenge of universality of art consists in being one of the privileged places for exploration of formal thought. Lévi-Strauss proposes to interpret simultaneously the constitution of image and the mental operations within each cultural universe. If Lévi-Strauss followed this path to make sense of the kadiwéu arabesques, it is proposed here to follow this trail in the analysis of abstract art. 